\title{
KULTURNI TURIZAM NA PRIMERU HRAMA SVETOG SAVE NA VRAČARU
}

\author{
Episkop remezijanski \\ Stefan (Šarić)
}

Srpska pravoslavna crkva
Correspondence:

Stafan Šarić

e-mail:

arhimandritstefan10@gmail.com

\section{Rezime:}

U ovom radu želim da ukažem na događaje koji su obogatili duhovni i kulturni život Hrama Svetog Save, ali su i pospešili razvoj turizma. Prvi deo rada predstavlja analizu odabranih događaja koji su predstavljeni u nekoliko kategorija: Književne večeri i tribine; Umetničke izložbe; Filmske i pozorišne projekcije; Edukativne radionice; Izdavačka delatnost; Nastupi muzičkih izvođača. Drugi deo rada predstavlja posebni projekat pod nazivom „Božićno seoce kod Hrama“ u kojem su objedinjene verske, kulturne i tradicionalne manifestacije, prožete kroz prethodno navedene primere. Zaključni deo rada predstavlja predloge budućih ideja i projekata koji mogu da doprinesu u još većoj meri duhovnom i kulturnom životu Hrama.

Ključne reči:

Hram, pravoslavlje, saradnja, zajednica, mogućnosti

\section{UVOD}

„Požurite se, braćo, i sa ljubavlju sačuvajte moje zapovesti, da budemo istiniti naslednici rajskih radosti i dostojni slave nebeske svetlosti, koju nam je dostojno moliti u Gospoda; ne ove svetlosti, koja na istoku ishodi i na zapadu zahodi, koja se vremenom svršava, i koja se deli dolaskom noći, koju zajednički sa životinjama vidimo; no molimo svetlosti, koju sa jedinim anđelima možemo videti, kojoj ni početak ne počinje, ni kraj ne prestaje. . "(Domentijan, 1983, p. 175).

Životom, verom i ljubavlju prema pravoslavnom narodu Sveti Sava je zadužio svakoga od nas da i mi utkamo dela ljubavi i žrtve prema pravoslavlju. Na osnovu tog zaveta i dela ljubavi svakoga ko pristupi, počela je izgradnja Hrama, večnog doma ovoga sveta. Zahvaljujući zainteresovanosti i predanosti mnogih naših predaka, približavamo se i finalnom delu ovog dugogodišnjeg poduhvata. Sve društvene i druge nedaće koje su zadesile pravoslavni narod, nisu uspele da ovu nameru, zadatak i žrtvu, niti da spreče, niti da zaustave. Ova svetinja živi i raste, neumorno i nepresušno, kao što je i sam Svetitelj bio primer istrajnosti u svim pravoslavnim poduhvatima. (Pešić, 2005.) I sada, u 21. veku mi nastavljamo ovu plemenitu akciju izgradnje samog Hrama i sabiranja pravoslavnog, ali i naroda drugih veroispovesti, kroz razne verske, kulturne i društvene manifestacije. Hram se gradi, ali on sam i izgrađuje; preobražava, oblikuje i usmerava, ne samo veru onih koji u njega ugrađuju, već i samu njihovu kulturu. 
Namera mi je da ovim radom predstavim Hram Svetog Save na Vračaru kao centar kulturnih i društvenih dešavanja, sa osvrtom na već postojeće manifestacije i sabranja i da ukažem na izuzetne mogućnosti i aktivnosti u budućnosti.

\section{KULTURNI I DUHOVNI ŽIVOT U HRAMU SVETOG SAVE}

„Veličinom svojih duhovnika i svojih mučenika, dostojanstvom svakoga vernika, hrišćanstvo je mesijansko, revolucionarno, eksplozivno." (Evdokimov, 2003, p. 241). I Hram, sam po sebi, nije samo mesto za molitvu, jer on, pored bogoslužbenog i molitvenog dela, predstavlja i svojevrsan centar kulture pravoslavlja. Iz široke lepeze kulturnih i duhovnih događanja, predstavićemo sledeće: Književne večeri i tribine; Umetničke izložbe; Filmske i pozorišne projekcije; Edukativne radionice; Izdavačku delatnost; Nastupe muzičkih izvođača.

\section{Književne večeri i tribine}

Dugogodišnju tradiciju naročito imaju književne večeri i duhovne tribine koje nastaju trudoljubivim radom bratstva ovoga Hrama u saradnji sa poznatim autorima književnih dela, gostima iz drugih crkvenih i kulturnih sfera. Svakog ponedeljka, parohijani, kao i svi zainteresovani, imaju mogućnost da prisustvuju nekom od ovih dešavanja u svečanoj sali parohijskog doma, ili na jednoj od promocija koje se održavaju u samoj Kripti Hrama dva do tri puta mesečno. Kao na primer saradnje i sa drugim državnim institucijama izdvajamo projekat Srpsko-ruskog mosta i predsedništva Republike Srpske pod nazivom "Dušu nisu ubili" i "Da se ne zaboravi" autora Mire Lolić-Močević i prof. Draga Mastilovića.

Slika 1. „Dušu nisu ubili“, promocija projekta u Kripti Hrama Svetog Save

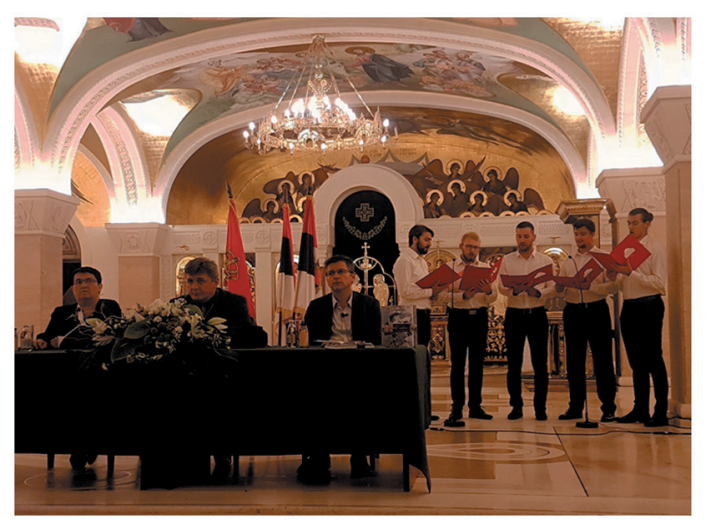

Izvor: http://hramsvetogsave.rs/

Slika 2. „Ikonostas svetlosti“, izložba poljskog autora Adama Stalonija-Dobžanskog

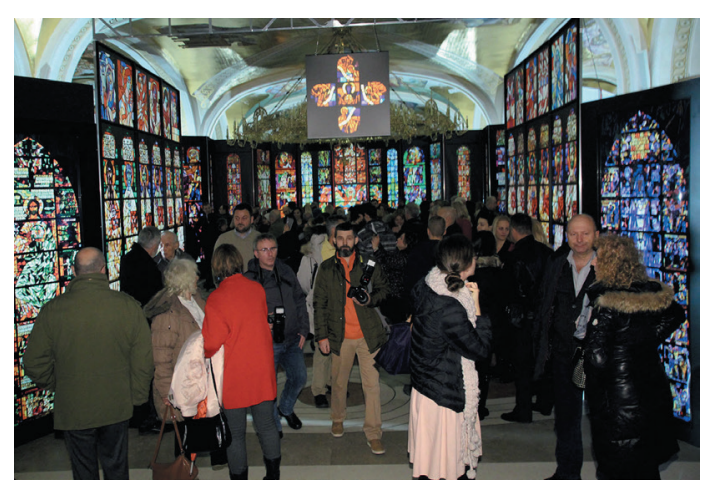




\section{Umetničke izložbe}

Veliku posećenost u jedinstvenom ambijentu Kripte, zabeležile su postavke izložbi naših poznatih likovnih umetnika, fotografa i ikonopisaca. Razmatrajući ikonu, kako navodi Sendler, bitno je zadržati troslojni pristup: naučno poznavanje, umetničku vrednost i bogoslovsko viđenje. Zaobilaženje jednog ili drugog od ovih slojeva ograničilo bi nas u punom smislu te reči. (Sendler, 2009, p. 15). Kao posebnu postavku izdvajamo izložbu pod nazivom „Ikonostas svetlosti“, poljskog autora Adama Stalonija-Dobžanskog koja je sa svojom instalacijom vitraža sa pravoslavnim ikonama privukla veliki broj domaćih i stranih posetilaca.

\section{Filmske i pozorišne projekcije}

Težeći da privučemo i mlađu populacionu grupu, jedan deo života Hrama posvećen je filmskim i pozorišnim projekcijama, sa ciljem da prezentuju što bogatije kulturne i duhovne predstave, kao i filmske zapise. Posebno izdvajamo pozorišnu predstavu „Jazavac pred sudom“ sa fantastičnim interaktivnim delom komunikacije sa publikom kao i projekcije ruskih bajki namenjene najmlađem uzrastu. U ovom segmentu, od značaja je i saradnja sa gradskim ustanovama te kao primer te saradnje navodimo i projekcije filmova sa duhovnom tematikom kao što je ruski „Ostrov“ koji je uvršten u repertoar ovogodišnjeg letnjeg otvorenog bioskopa na platou ispred Hrama.

\section{Edukativne radionice}

Kroz razne edukativne radionice, okupljamo veliki broj mladih ljudi i studenata iz drugih zemalja, težeći ka njihovoj integraciji u duhu pravoslavlja i umrežavanju raznih aktera i organizacija. Prilikom organizovanih poseta Hramu i realizacije plana boravka i aktivnosti, mladim ljudima pruža se mogućnost da kroz druženje i uče i upoznaju srpsku tradiciju, kulturu i duhovne vrednosti. U saradnji sa Međunarodnim fondom jedinstva pravoslavnih naroda, realizovali smo posetu Hramu Svetog Save i manastirima Kovilj, Studenica i Krušedol, kao i osmišljen sedmodnevni boravak u našoj zemlji, grupi studenata sa Univerziteta iz Luganska. Takođe, organizujemo učenje ruskog jezika, časove pevanja i crkvenog pojanja, za manje i veće grupe zainteresovanih.

\section{Izdavačka delatnost}

Zbog sve učestalije upotrebe informacionih tehnologija formirali smo zvaničnu internet stranicu Hrama kao i naloge na popularnim društvenim mrežama kako bismo, i na taj način, bili dostupni svima onima koji žele da budu u toku sa dešavanjima iz života Hrama. Poštujući potrebu i za pisanom rečju, osmislili smo novi, savremeniji koncept parohijskog časopisa „Svetosavac“ sa dodatkom „Malog Svetosavca“. U saradnji sa drugim medijskim i produkcijskim kućama, postižemo ažurnost novih informacija o aktuelnim dešavanjima u Hramu.

\section{Nastupi muzičkih izvođača}

U okviru kulturnih i duhovnih dešavanja u Hramu, svoje probe i nastupe imaju i domaćini a to su, pored reprezentativnog hora Hrama Svetog Save i pevačko društvo „Mokranjac“ i dečji hor „Rastko“. Hram Svetog Save je, tradicionalno, desetu godinu zaredom, organizator i domaćin Vaskršnjeg koncerta horova sa učesnicima iz cele Srbije i šire, uz direktan prenos nacionalne televizije Republike Srbije. U pripremi je novi projekat i međunarodna saradnja u kom će preko 80 prijavljenih kandidata učestvovati u muzičkim probama u samom parohijskom domu, pod vođstvom čuvenog crkvenog kompozitora i dirigenta, monahinje Julijane (Irine) Denisove, a čiji je vrhunac finalni zajednički nastup- Duhovna akademija, u Kripti Hrama.

Prethodno navedeni događaji jesu obogatili aktuelni život samog Hrama i crkvene zajednice, ali sa posebnom pažnjom želimo Vam predstaviti realizovani projekat pod nazivom „Božićno seoce kod Hrama“ kao izvanredan primer objedinjena svega prethodnog i kao odličnu podlogu za spoj kulturnog i verskog turizma. 


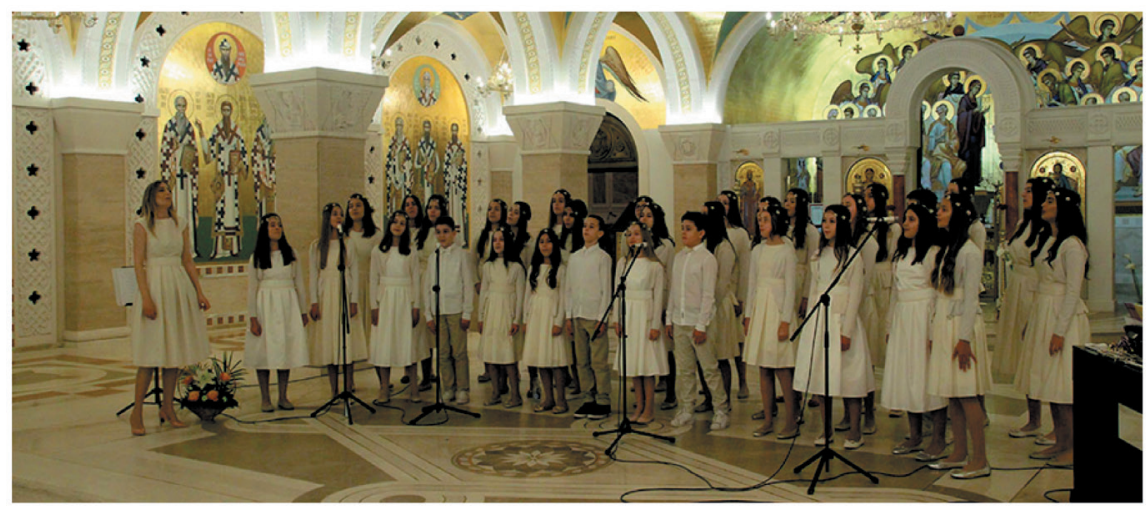

Izvor: http://hramsvetogsave.rs/

\section{BOŽIĆNO SEOCE KOD HRAMA- SPOJ VERE, KULTURE I TRADICIJE}

„Želeći da čoveka dovede u zajednicu, crkva se vekovima prilagođavala savremenim trendovima, ali ipak i ostajala svoja nudeći čoveku smisao života na zemlji sa željom oplemenjivanja same ličnosti i razvitka svih njegovih čula, pozivajući istog onom jevanđeljskom porukom: „Dođi i vidi.“(Jovan 1:46). U današnje vreme, vreme virtuelnog društva, postavlja se pitanje kako čoveka osloboditi zavisnosti od tehnoloških inovacija, dovesti u hram i osloboditi svakodnevnice." (Šarić, 2017).

Ideja „Božićnog seoceta kod Hrama“ bila je da se na prostoru ispred naše najveće pravoslavne svetinje, uz učešće što većeg broja različitih institucija i aktera iz različitih sfera kulturnog života, organizuje i realizuje jedinstven pionirski poduhvat koji će privući, ne samo vernike, već i domaće i strane turiste. Manifestacija ovog tipa, prvi put je organizovana na ovaj način i na ovoj lokaciji. Božićno seoce kod Hrama svečano je otvorio Njegova Svetost Patrijarh srpski G.G. Irinej, koji je, uz Versko Dobrotvorno Starateljstvo i Svetosavsko zvonce, pripremio i podelio poklon paketiće za više od hiljadu mališana.

Iste večeri, četvrtog januara, uz svečani defile Reprezentativnog orkestra garde Vojske Srbije, zvanično je otvorena manifestacija. U periodu od četvrtog, pa sve do dvadesetosmog januara, na platou ispred Hrama smenjivao se veliki broj učesnika sa najraznovrsnijim programskim sadržajima. Veliku pažnju privukao je i muzički projekat El Sistema Srbije, program socijalne inkluzije i kulturne transformacije namenjene socijalno ugroženim grupama, sa učešćem dece iz Niša, Zrenjanina i Vranja, pod dirigentskom palicom čuvenog Herarda Estrade.

„Božićno seoce“ okupilo je 27 dečjih horova sa preko 950-oro dece iz cele Srbije, više od 300 učesnika sa 12 izvedenih pozorišnih predstava, 31 muzički nastup i oko 100 sati realizovanog programa. (http://communications.rs/). Važno je napomenuti da su ovaj projekat podržale najrazličitije institucije i pojedinci, te je kao takav zaista privukao ogroman broj posetilaca. Smatra se da broj turista koji je posetio plato ispred Hrama, prema nezvaničnim statistikama, iznosi negde oko stotinak hiljada. Pored Raspevane božićne jelke, konstrukcije muzičke bine u obliku jelke za nastup dečjih horova, veliku atrakciju predstavljala je i gradska fontana ispunjena slamom sa instalacijom prikaza pravoslavnih motiva rođenja Isusa Hrista. Plato oko Hrama, dobivši praznično osvetljenje po prvi put, krasile su, pored drvenih, bajkovitih kućica sa mnoštvom božićnih slatkiša i suvenira, i posebno dizajnirane svetleće praznične instalacije, koje su upotpunile i sam čin paljenja badnjaka i lomljenja božićne česnice. Uz muzičke nastupe, premijerne komade pozorišnih predstava i projekcije sinhronizovanih ruskih bajki, ova manifestacija je u prvoj godini svog održavanja izbila u sam vrh dešavanja u Beogradu.

„Božićno seoce“ ispratila je 101 medijska kuća i pomenuto je u 467 priloga. (http://www.ninamedia.rs/). Značajno je napomenuti i da je preko $80 \%$ novca obezbeđeno od strane pokrovitelja. Počev od Badnje večeri, pa sve do praznika Svetog Save, kompletan crkveni i bogoslužbeni deo vezan za određene verske praznike u tom periodu, na autentičan način, ukomponovan je sa savremenim kulturno-umetničkim sadržajem i kao takav predstavlja jedinstven spoj vere, kulture i tradicije. 


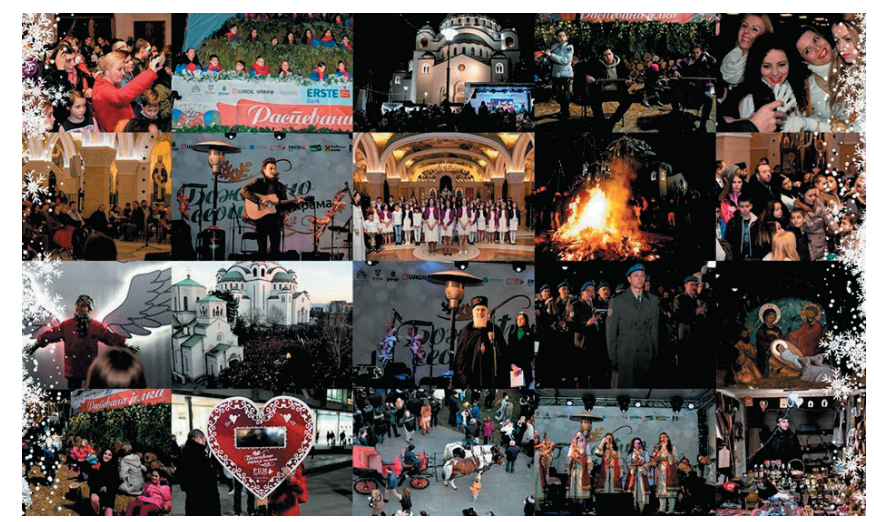

Izvor: http://communications.rs/

\section{UMESTO ZAKLJUČKA}

Na kraju želim da ukažem na nekoliko novih ideja, neophodnosti i potreba koje će doprineti razvoju verskog odnosno kulturnog turizma. Preduslov za strateški razvoj verskog turizma jeste partnerski odnos crkve i države (Radisavljević-Ćiparizović, 2013). Od ključnog značaja jeste uspostavljanje saradnje sa nadležnim institucijama, počev od Ministarstva trgovine, turizma i telekomunikacija, preko Turističke Organizacije Srbije, Turističke Organizacije Beograda, Udruženja turističkih vodiča Srbije, pa sve do gradskih i lokalnih turističkih agencija. Postojećom Strategijom o razvoju turizma republike Srbije potrebno je precizirati pojmove i oblast verskog i kulturnog turizma čime bi se jasno definisali ciljevi, predmeti i neophodna sredstva i uklonili svi nedostaci i poteškoće na koje nailazimo u pokušaju praktične primene. Na taj način pravno bi se regulisale organizovane posete domaćih i stranih turista, uz prethodno ustanovljena i regulisanja pravila ponašanja, kako domaćina, tako i turističkih vodiča, pa i samih posetilaca. Pored ugostiteljskih objekata, i objekti Srpske Pravoslavne Crkve, manastiri, konaci, parohijski domovi, ispunjavali bi propisane standarde, uključujući i adekvatno i profesionalno obučena lica za prijem posetilaca. Veliki potencijal nalazi se i u ostvarivanju međunarodne saradnje i sa međupomesnim crkvama, pisanjem i realizacijom zajedničkih projekata koji imaju za cilj da našu kulturu približe drugim zajednicama. Jedan od predloga jeste i organizacija Međunarodnog letnjeg kampa za mlade u nastupajućoj godini jubileja, kao primer podrške mladima i pokušaj zajedničkog uključivanja u verske i kulturne aktivnosti. Formiranjem jedinstvenog Svetosavskog centra pri Hramu Svetog Save sa edukativnim radionicama, kreativnim pristupom, stručnom katedrom, savremenom tehničkom opremom, jedinstvenim prostorom uz blagoslov i brižnu ljubav naše Svete Crkve, svako, i pojedinačno delo, postalo bi primer poslovnog i duhovnog napretka, kako individue, tako i celokupne zajednice.

\section{LITERATURA}

Domentijan. (1938). Život Sv. Save i Sv. Simeona. U: Mitropolit dabrobosanski, Gospodin Nikolaj, O Svetom Savi (211-212). (2006). Izdavački fond Arhiepiskopije beogradsko-karlovačke i Pravoslavni bogoslovski fakultet Sarajevskog univerziteta, Foča.

Evdokimov, P. N. (2003). Vekovi duhovnog života. Novi Sad: Budućnost.

Pešić, B. (2005). Hram Svetog Save u Beogradu. Novi Sad: Pravoslavna reč.

Radisavljević-Ćiparizović, D. (2013). Religija i hodočasnički turizam: studija slučaja tri svetilišta u Srbiji (Kalemegdanska Sv. Petka, Bogorodica Đuniska i Majka Božja Tekijska), doktorska disertacija. Beograd: Filozofski fakultet Univerziteta u Beogradu.

Sendler, E. (2009). Ikona- Slika nevidljivog: elementi bogoslovlja, estetike i mehanike ikonopisa. Beograd: Jasen. 
Šarić, S. (2017). Verski turizam - primeri pionirskog poduhvata manastira Lepavina i Tumane. Međunarodna konferencija SITCON 2017. Beograd: Univerzitet Singidunum.

http://communications.rs/

http://www.ninamedia.rs/

http://hramsvetogsave.rs/

\title{
CULTURAL TOURISM ON THE EXAMPLE ON ST. SAVA TEMPLE IN VRAČAR
}

\begin{abstract}
:
In this paper I would like to point out the events that not just have enriched the spiritual and cultural life of the Temple, but also accelerated the development of the tourism. The first part represents an analysis of selected events that are depicted in several categories: Literary evenings and tribunes, Art exhibitions, Film and theater projections, Educational workshops, Publishing, Musician s performances. The second part of the paper represents the special project named „Christmas village at the Temple" in which religious, cultural and traditional manifestations are united and flocked through the above-mentioned examples. The final part of the paper contains suggestions of future ideas and projects that can contribute to the spiritual and cultural life of the Temple to a greater extent.
\end{abstract}

Keywords:

the Temple, orthodoxy, collaboration, community, possibilities 